University of Wollongong

Research Online

Faculty of Engineering and Information

Faculty of Engineering and Information

Sciences - Papers: Part A

Sciences

$1-1-2013$

Description and comparison of quality of electronic versus paper-based resident admission forms in Australian aged care facilities

Ning Wang

University of Wollongong, nw57@uowmail.edu.au

Ping Yu

University of Wollongong, ping@uow.edu.au

David Hailey

University of Wollongong, dhailey@uow.edu.au

Follow this and additional works at: https://ro.uow.edu.au/eispapers

Part of the Engineering Commons, and the Science and Technology Studies Commons

Research Online is the open access institutional repository for the University of Wollongong. For further information contact the UOW Library: research-pubs@uow.edu.au 


\title{
Description and comparison of quality of electronic versus paper-based resident admission forms in Australian aged care facilities
}

\begin{abstract}
Purpose To describe the paper-based and electronic formats of resident admission forms used in several aged care facilities in Australia and to compare the extent to which resident admission information was documented in paper-based and the electronic health records. Methods Retrospective auditing and comparison of the documentation quality of paper-based and electronic resident admission forms were conducted. A checklist of admission data was qualitatively derived from different formats of the admission forms collected. Three measures were used to assess the quality of documentation of the admission forms, including completeness rate, comprehensiveness rate and frequency of documented data element. The associations between the number of items and their completeness and comprehensiveness rates were estimated at a general level and at each information category level. Results Various paper-based and electronic formats of admission forms were collected, reflecting varying practice among the participant facilities. The overall completeness and comprehensiveness rates of the admission forms were poor, but were higher in the electronic health records than in the paper-based records $(60 \%$ versus $56 \%$ and $40 \%$ versus $29 \%$ respectively, $p<0.01)$. There were differences in the overall completeness and comprehensiveness rates between the different formats of admission forms $(p<$ 0.01). At each information category level, varying degrees of difference in the completeness and comprehensiveness rates were found between different form formats and between the paper-based and the electronic records. A negative association between the completeness rate and the number of items in a form was found at each information category level $(p<0.01)$, i.e., more data items designed in a form, the less likely that the items would be completely filled. However, the associations between the comprehensiveness rates and the number of items were highly positive at both overall and individual information category levels $(p<0.01)$, suggesting more items designed in a form, more information would be captured. Conclusion Better quality of documentation in resident admission forms was identified in the electronic documentation systems than in previous paper-based systems, but still needs to be further improved in practice. The quality of documentation of resident admission data should be further analysed in relation to its specific content.
\end{abstract}

\section{Keywords}

aged, australian, forms, admission, resident, facilities, paper, care, versus, electronic, quality, comparison, description

Disciplines

Engineering | Science and Technology Studies

\section{Publication Details}

Wang, N., Yu, P. \& Hailey, D. (2013). Description and comparison of quality of electronic versus paperbased resident admission forms in Australian aged care facilities. International Journal of Medical Informatics, 82 (5), 313-324. 


\section{Title page}

Title of the manuscript: Description and comparison of quality of electronic versus paperbased resident admission forms in Australian aged care facilities

\section{Authors of the manuscript:}

Ning Wang' RN, PhD candidate, MPH

Ping $\mathrm{Yu}, \mathrm{PhD}$

David Hailey, PhD

Affiliation: Health Informatics Research Laboratory, School of Information System and

Technology, Faculty of Informatics, University of Wollongong

The corresponding author: Ping Yu: PhD, Senior Lecturer

Health Informatics Research Laboratory, School of Information System and Technology, Faculty of Informatics, University of Wollongong, Northfields Ave, Wollongong NSW 2522, Australia

Email: ping@uow.edu.au

Phone: +61 242215412

Fax: +61 242214045

Website: http://www.uow.edu.au/ ping/

Key words: electronic health record, paper record, electronic record, nursing documentation, admission form, auditing, quality, evaluation. 


\section{Abstract}

Purpose: To describe the paper-based and electronic formats of resident admission forms used in several aged care facilities in Australia and to compare the extent to which resident admission information was documented in paper-based and the electronic health records. Methods: Retrospective auditing and comparison of the documentation quality of paperbased and electronic resident admission forms were conducted. A checklist of admission data was qualitatively derived from different formats of the admission forms collected. Three measures were used to assess the quality of documentation of the admission forms, including completeness rate, comprehensiveness rate and the frequency of documented data element. The associations between the number of items and their completeness and comprehensiveness rates were estimated at a general level and at each information category level.

Results: Various paper-based and electronic formats of admission forms were collected, reflecting varying practice among the participant facilities. The overall completeness and comprehensiveness rates of the admission forms were poor, but were higher in the electronic health records than in the paper-based records (60\% vs $56 \%$ and $40 \%$ vs $29 \%$ respectively, $\mathrm{p}<0.01)$. There were differences in the overall completeness and comprehensiveness rates between the different formats of admission forms $(\mathrm{p}<0.01)$. At each information category level, varying degrees of difference in the completeness and comprehensiveness rates were found between different form formats and between the paper-based and the electronic records. A negative association between the completeness rate and the number of items in a form was found at each information category level 
$(\mathrm{p}<0.01)$, i.e., more data items designed in a form, the less likely that the items would be completely filled. However, the associations between the comprehensiveness rates and the number of items were highly positive at both overall and individual information category levels ( $\mathrm{p}<0.01$ ), suggesting more items designed in a form, more information would be captured.

Conclusion: Better quality of documentation in resident admission forms was identified in the electronic documentation systems than in previous paper-based systems, but still needs to be further improved in practice. The quality of documentation of resident admission data should be further analyzed in relation to its specific content. 


\section{Introduction}

The importance of information about clients and care in the operation of modern health care organisations has been well recognized [1, 2, 3]. Information systems that facilitate data collection and tracking for patient care can also sustain care quality improvement [4]. In the past decades, application of electronic health records (EHRs) has streamlined data processing and management in many health care settings with benefits of increasing access to more complete, accurate and up-to-date data and reducing redundancy $[1,5,6,7]$. In aged care settings, the implementation of EHRs has potential to improve quality of care, efficiency of operation and integration of services [4].

Given the fundamental significance of nursing documentation in Australian aged care sector for the purposes of funding, accreditation and quality improvement $[8,9,10]$, several aged care organisations in Australia have implemented EHRs. Caregivers perceived the benefits of the implementation of the EHRs as the provision of more accurate, legible and complete information and reduction of repetition in data entry [11]. In this paper, we report an audit study to investigate the actual effect of the EHRs on the quality of nursing documentation.

As a significant part of resident records in aged care, resident admission forms contain information about residents' personal and health history, support networks and discharge planning. Such resident data are essential for administrative purposes, resident assessment, and care planning. Quality resident admission data may also play a vital role in service coordination, public health research and health planning. 
Numerous studies have been carried out to investigate the impact of EHRs on the information quality of a range of documentation components and improved completeness of documentation with EHRs has been reported [12]. However, more omissions and errors in the EHRs were also reported [13]. Several studies conducted in acute settings have reported poor completeness of selected elements of admission information such as admission diagnosis, allergies, medication, occupation, social class, name/telephone of contact person and religion [14,15,16,17]. In regard to EHRs, Prins et al. [16] identified inadequate documentation of admission diagnoses and reason for admission. Pringle et al.’s study [18] showed that the documentation of occupation was incomplete and no information about social class and ethnicity had been recorded. In addition, FloorSchreudering et al. [19] have reported poor documentation in EHRs of patients' telephone numbers and drug history after their first visit to a local pharmacy.

However, inadequate research attention has been paid to the quality of overall admission information. To date, there has been no study on the quality of admission data in the aged care setting. Therefore, our study investigated the quality of resident admission data documented in paper-based and electronic admission forms in several aged care facilities from different organisations where commercial EHRs had been implemented. The objectives of the study were to describe the paper-based and electronic formats of resident admission forms used in the aged care facilities; and to compare the extent to which resident admission information was documented in these formats. 


\section{Methods}

\subsection{Study design}

This was a nursing documentation audit study. Retrospective review and comparison of the documentation quality of paper-based and electronic resident admission forms were conducted.

\subsection{Setting}

The study was carried out at nine residential aged care facilities (RACFs) from three aged care organisations in Australia (coded as Organisation 1, 2 and 3 respectively). These organisations have implemented two commercial EHR systems at different time points since 2005: Software 1 was implemented in Organisation 1 and Software 2 was implemented in Organisation 2 and 3.

\subsection{Sample}

The study samples were the resident records conveniently selected from the nine RACFs. These included 251 electronic and 147 paper-based resident admission forms from the resident records. The number of samples varied among the nine facilities due to differences in the number of residents who gave their consent and the unavailability of archived paperbased records at some facilities.

\subsection{Participants}

Participants were the residents of the RACFs whose admission forms were accessed by the researchers after consent had been provided. Before seeking written consent, an information sheet with detailed description about the study including data handling 
procedures was given to the residents or to their representatives, depending on the residents’ cognitive capacity.

\subsection{Ethics approval}

The study was approved by University of Wollongong/Illawarra Area Health Service Human Research Ethics Committee and the ethics committee of a participating aged care organisation.

\subsection{Development of an auditing checklist}

A checklist to compare the documentation quality of the different admission form formats used by the RACFs was developed using data elements that were qualitatively derived from the admission forms using a similar approach to that of Schleyer et al. [20]. The different formats of forms used by the RACFs shared some common items, but varied in their content. As the study was intended to present a full picture about the scope of information to be collected from the residents by using the admission forms, the checklist included all items in the included admission forms, except those about resident discharge information. Discharge - related items were excluded because most of the participating residents' admission status was current. Inclusion of all items from the different admission forms recognized that they had been developed and validated by experienced nursing managers in each aged care organisation. Thus the nursing knowledge captured in the admission forms was valuable and should be respected.

During the development of the checklist, all items from each format of the admission forms were extracted and then grouped into categories. Under each category, any duplicated items 
were merged to form a single data element for the checklist, including items referring to the same concept, but named differently (e.g., ‘Admission Date’ and ‘Date of Entry’).

For items designed to collect similar type of data but with different levels of granularity from general to specific, a summary term was adopted to form a single data element. For example, 'Medical/Surgical Diagnosis’ was used in the checklist for several items such as 'Provisional Diagnosis’, ‘Principal Diagnosis’, ‘Principal Operation and Major Procedure’ and 'Other Operations or Procedures'. Additionally, some separate items that are related to each other were combined to a single data element. For example, 'Surname' and 'First Name' were combined to form a data element of 'Full Name'.

Table I. Categories and data elements of the checklist

\begin{tabular}{|c|c|}
\hline $\begin{array}{l}\text { Categories } \\
\text { (number of data } \\
\text { elements) }\end{array}$ & Data elements \\
\hline $\begin{array}{l}\text { Resident } \\
\text { Demographics } \\
(\mathrm{n}=16)\end{array}$ & $\begin{array}{l}\text { Title, full name, preferred name, date of birth, age, resident usual address, resident phone number, } \\
\text { gender, primary language, secondary language, interpreter needed, religion, marital status, country of } \\
\text { birth, Aboriginal or Torres Strait Islander, working company }\end{array}$ \\
\hline $\begin{array}{l}\text { Admission Details } \\
(\mathrm{n}=16)\end{array}$ & $\begin{array}{l}\text { Aged care facility, room, bed, location, medication trolley, photo taken date, other information, } \\
\text { medical record number, resident status (e.g. active), entry type, admission date, admitted from/source } \\
\text { of referral, resident category, UR number, medical record number }\end{array}$ \\
\hline $\begin{array}{l}\text { Resident Health } \\
\text { History }(n=9)\end{array}$ & $\begin{array}{l}\text { Allergies (drugs/other), medical/surgical diagnosis, psychiatric history, other conditions, drugs on } \\
\text { admission/medication notes, Flu vaccination, chest x-ray, external cause of injury or poisoning, place } \\
\text { of occurrence }\end{array}$ \\
\hline $\begin{array}{l}\text { Baseline Health } \\
\text { Ranges }(n=4)\end{array}$ & Height, weight, blood sugar level, blood pressure \\
\hline Membership & Pension type, pension/benefit care number \\
\hline \multirow{5}{*}{ Details $(n=16)$} & Centrelink number \\
\hline & $\begin{array}{l}\text { DVA card number or DVA card member number) } \\
\text { name as it appears on the card, expiry date }\end{array}$ \\
\hline & Private health insurance provider/fund name, membership number/table \\
\hline & Ambulance fund (y/n), member number, transport access scheme \\
\hline & Hospital of choice, diabetic association number, electoral roll (Yes/No), war service \\
\hline $\begin{array}{l}\text { End of Life Wishes } \\
(\mathrm{n}=5)\end{array}$ & $\begin{array}{l}\text { Funeral arrangement (cremation/burial), funeral director/undertaker, phone number, advanced care } \\
\text { directive (Yes/No), summary of wishes/requirements }\end{array}$ \\
\hline Doctor $(n=5)$ & Medical officer name, address, phone, email, fax \\
\hline \multirow{2}{*}{$\begin{array}{l}\text { General Contact } \\
(\mathrm{n}=18)\end{array}$} & Primary contact name, relationship, address, phone, email, fax \\
\hline & $\begin{array}{l}\text { Secondary contact name, relationship, address, phone, email, fax } \\
\text { Next of kin } 1 \text { name, relationship, address, phone, email, fax }\end{array}$ \\
\hline \multirow{2}{*}{$\begin{array}{l}\text { Legal Contact } \\
(n=13)\end{array}$} & Power of attorney type, power of attorney name, address, power of attorney phone number, email \\
\hline & Guardianship type (public/private), name, address, phone, email \\
\hline
\end{tabular}


The checklist was used to determine whether or not information on individual items had been entered into individual admission forms. No attempt was made to determine whether the items were applicable to individuals as the researchers did not have direct contact with the residents. Nor was the quality of narrative entries for some items considered. The validity of the checklist was based on how well its contents captured the details from all the resident admission form formats. The checklist was judged by three health informatics researchers who considered and reached consensus on the appropriateness of categorization of the items. The checklist contained 10 categories with 105 data elements. These entirely covered the data intended to be collected by various admission forms from residents at their admission. Detailed information about the checklist is displayed in Table I.

A dichotomous scale with 'yes/no' options was adopted to score each admission form depending on the occurrence of documentation for each of the data elements. One point was given to a 'yes' option and zero was given to a 'no' opinion. Two researchers agreed on the protocol for rating the admission forms and then graded the forms in the sample from the RACFs using the checklist spreadsheet listing the data elements. During this process, any question or disagreement was discussed to reach consensus.

\subsection{Measurement approaches}

Quantitative description of documentation of admission forms was made through mapping items completed in an admission form to the items pre-formatted in the form and to the data 
elements of the checklist. Two measures were given for this assessment: completeness rate and comprehensiveness rate.

Completeness rate was defined as the proportion of completed items to the total items in a form. It reflects the extent to which data items in a form were completed by a nurse. A formula for calculating the completeness rate of a form is:

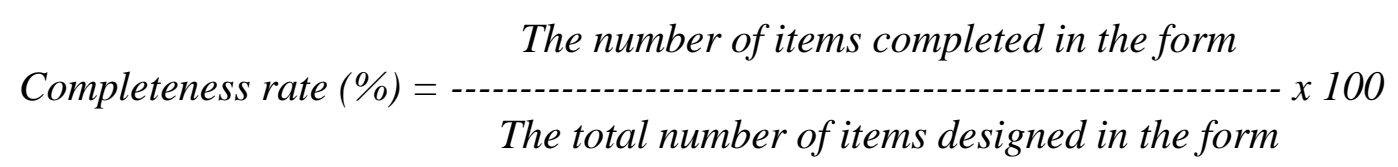

However, as different form formats may have varying numbers of items; a high completeness rate of a form may not necessarily mean that more data were captured in this form than another one. Therefore, a second parameter, comprehensiveness rate was used to capture the proportion of completed items in a form to the total data elements in the checklist. It reflects the amount of data documented by a nurse relative to the full range of information defined in the checklist based on practice. This measure allows the comparison of amount of data recorded in different formats of forms. A formula for calculating the comprehensiveness rate of a form is:

$$
\text { Comprehensiveness rate }(\%)=\text { The number of items completed in the form }
$$

The number of data elements in the checklist (105)

Both completeness rate and comprehensiveness rate were calculated in overall and at individual information category levels to provide general and specific assessment of completion status of different admission forms. 
A comparison was made of the completeness and comprehensiveness rates for the different form formats. Comparison of each rate was made for any two of the seven formats. A similar comparison was made between the overall rates for all paper - based forms and all EHRs.

In addition, the frequency proportion of documentation of each data element was used as a further measurement of documentation for a comparison between the paper-based and electronic admission forms. It was defined as the ratio of occurrences of documentation of each data element to the number of forms analyzed. This measure reflected what items were frequently or infrequently collected by the nurses in the paper-based and electronic admission forms. A formula for calculating the frequency proportion of a data element among the samples is:

The number of occurrences of documentation among the forms Frequency proportion $=$

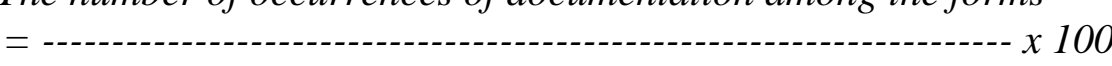

The number of forms

\subsection{Data analysis}

Raw data was entered into an Excel spreadsheet, and then imported into a SPSS file (software 18.0) for statistical analysis. Statistical methods used included descriptive statistics and non-parametric statistical analysis. The completeness and comprehensiveness rates of admission forms were examined by the Kruskal-Wallis $\mathrm{H}$ test to identify any statistically significant differences among the seven formats. If a significant difference was identified, the Mann-Whitney U test was used for the identification of significant differences between any two of seven form formats. 
In addition, nonparametric correlation analysis with Spearman's rho test was used to examine the associations between the numbers of items and the completeness rate and comprehensiveness rate of a form format in total and at each information category level. As nonparametric tests were conducted, statistical data presented in the paper are median values. The measurement results are presented as percentage of values.

\section{Results}

\subsection{The use and characteristics of different formats of resident admission forms among} aged care facilities

A total of 399 admission forms was collected from the nine aged care facilities. There were six formats of paper-based admission forms and two formats of electronic admission forms. As one paper-based form format was only used for one resident, it was excluded from the analysis, leaving 398 forms in seven formats for the final analysis. A summary of the format of forms used by the participating organisations and facilities is displayed in Table

II.

Table II. Admission form formats and the number of samples

\begin{tabular}{|c|c|c|c|c|c|c|c|c|c|}
\hline & \multicolumn{2}{|c|}{ Organisation 1} & \multicolumn{4}{|c|}{ Organisation 2} & \multicolumn{3}{|c|}{ Organisation 3} \\
\hline Facility & A & $\mathrm{B}$ & $\mathrm{C}$ & $\mathrm{D}$ & $\mathrm{E}$ & F & G & $\mathrm{H}$ & I \\
\hline $\begin{array}{l}\text { Paper-based } \\
\text { admission form } \\
\text { format (sample } \\
\text { size } n=147 \text { ) }\end{array}$ & $\mathrm{n} / \mathrm{a}$ & $\begin{array}{l}\text { Form } 5 \\
(\mathrm{n}=28)\end{array}$ & $\begin{array}{l}\text { Form1(n= } \\
22) \\
\text { Form2 } \\
(\mathrm{n}=11)\end{array}$ & $\begin{array}{l}\text { Form } 1(\mathrm{n}= \\
8) \\
\text { Form2 } \\
(\mathrm{n}=1)\end{array}$ & $\begin{array}{l}\text { Form } 2 \\
(\mathrm{n}=6)\end{array}$ & $\begin{array}{l}\text { Form } 1 \\
(\mathrm{n}=8)\end{array}$ & $\begin{array}{l}\text { Form1 } \\
(\mathrm{n}=35) \\
\text { Form3 } \\
(\mathrm{n}=1) \\
\text { Form4 } \\
(\mathrm{n}=15)\end{array}$ & $\begin{array}{l}\text { Form3 } \\
(\mathrm{n}=7)\end{array}$ & $\begin{array}{l}\text { Form3 } \\
(n=5)\end{array}$ \\
\hline $\begin{array}{c}\text { Electronic } \\
\text { admission form } \\
\text { format (sample } \\
\text { size } n=251 \text { ) }\end{array}$ & $\begin{array}{l}\text { e-Form } \\
7(n=28)\end{array}$ & $\mathrm{n} / \mathrm{a}$ & $\begin{array}{l}\text { e-Form } 6 \\
(\mathrm{n}=39)\end{array}$ & $\begin{array}{l}\text { e-Form } 6 \\
(\mathrm{n}=40)\end{array}$ & $\begin{array}{l}\text { e-Form } 6 \\
(\mathrm{n}=25)\end{array}$ & $\begin{array}{l}\text { e-Form } 6 \\
(n=36)\end{array}$ & $\begin{array}{l}\text { e-Form } 6 \\
(\mathrm{n}=11)\end{array}$ & $\begin{array}{l}\text { e-Form } 6 \\
(\mathrm{n}=34)\end{array}$ & $\begin{array}{l}\text { e-Form } 6 \\
(n=38)\end{array}$ \\
\hline
\end{tabular}

Six out of 10 categories of data items were common to all types of forms. They include demographics, admission details, health history, membership, doctor and general contact. 
e-Form6 was an automation of a paper-based Form 3 and e-Form7 was an automation of Form5. However, both electronic formats have additional items to those in the paper-based formats from which they were derived. e-Form 6 had 11 items in addition to the 68 items in Form 3. e-Form 7 derived 40 out of 47 items from Form 5 and had 27 additional items. The number of items in each format of the admission forms is presented in Table III.

\subsection{Completeness of documentation among different formats of admission forms and} between paper-based records and EHRs

The median overall completeness rates ranged from 38.1\% $(n=18)$ for paper-based Form 2 to $59.7 \%(n=28)$ for e-Form 7 . The differences in completeness rates among the seven formats was significant $(\mathrm{p}<0.01)$. A comparison of any two of the seven form formats showed significant differences in 13 out of 21 pairs $\left(\mathrm{p}^{<0.05)}\right.$.

Significant differences in completeness rates were found among the seven form formats for all of the information categories $(\mathrm{p}<0.05)$ except "baseline health ranges' and 'legal contact'

A comparison of completeness rates was also made between any two of seven form formats at each information category level. The results showed that 94 out of 154 pairs (61\%) had significant differences $(\mathrm{p}<0.05)$ (Table III).

The overall completeness rate in the electronic formats of admission forms was slightly higher than that in paper-based formats of forms (59.5\%, interquartile range 0.14 vs 55.8\%, interquartile range $0.10, \mathrm{p}<0.01$ ). At the level of each information category, a statistically significant increase in completeness rate was found in electronic forms for several 
information categories $(\mathrm{p}<0.01)$. The greatest differences in completeness rate between the electronic and paper forms were in the categories of 'Health History' (increased 23.8\%); 'Membership' (increased 21.8\%) and 'Demographics' (increased 9.0\%). In contrast, there was a reduced completeness rate in the electronic admission forms in comparison with the paper forms in the information category of 'General Contact' by $14.2 \%$. There was no statistically significant difference between the two types of forms in the categories of 'End of Life Wishes', 'Doctor’ and 'Legal Contact.

As e-Form 6 and e-Form 7were the automation of Form 3 and Form 5 respectively, a comparison of completeness rate of their common items (68 and 40 respectively) within each pair was conducted. The results showed that the completeness rates of the two formats of electronic admission forms were significantly higher than that of their counterparts $(\mathrm{P}<0.01)$ (Figure 1).

Figure 1. Comparison of mean completeness rates of common items between the paper-based and electronic admission forms by each pair

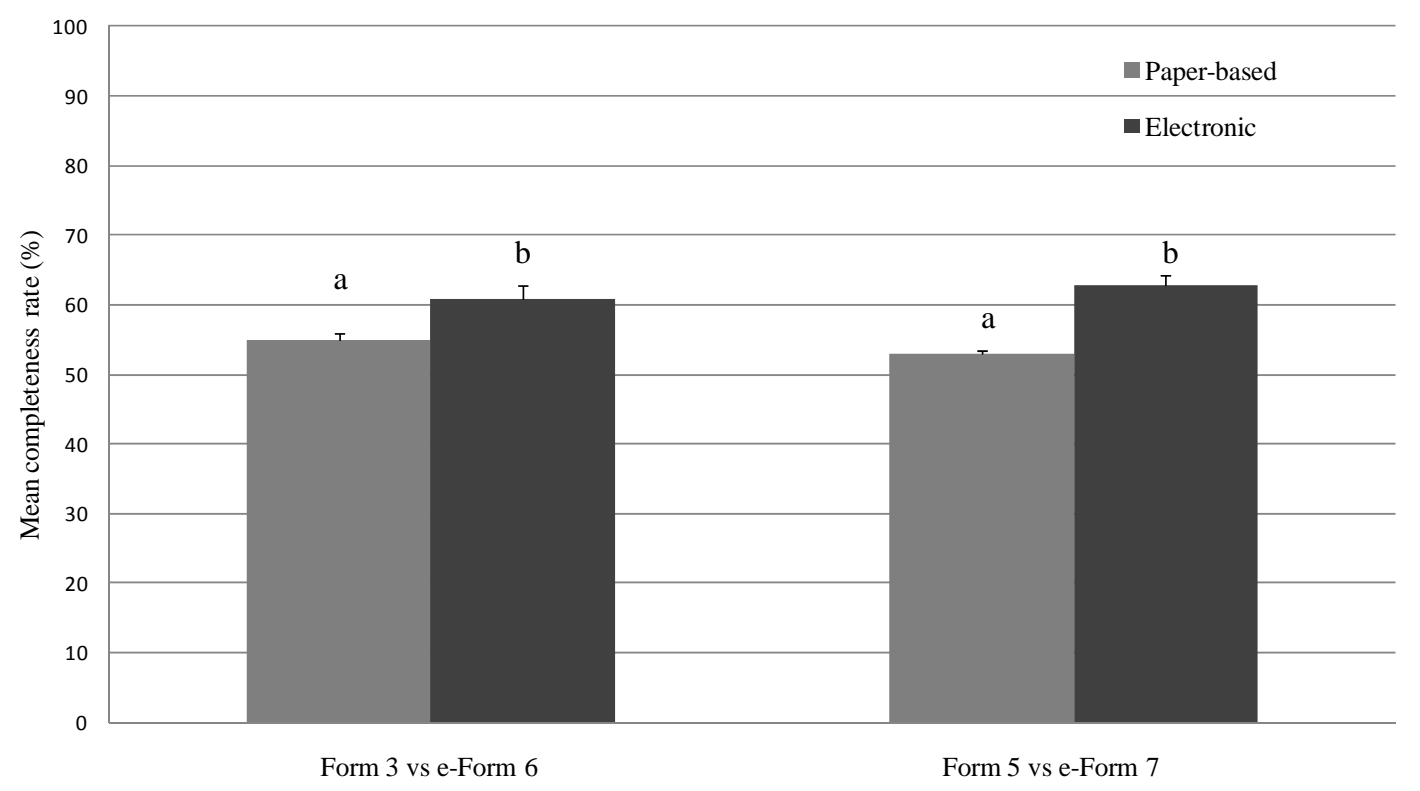


Note: the bar on the top of histogram is standard error

\subsection{Comprehensiveness of documentation in the paper-based records and EHRs}

Variation in the comprehensiveness rate was found among different form formats in total and for each information category (Table III). The overall comprehensiveness rates for seven formats ranged from $21 \%$ for Form 5 to $41 \%$ for e-Form 6 . The difference among them was significant $(\mathrm{p}<0.01)$.

A comparison of the overall comprehensiveness rate between any two of the seven form formats indicated that 17 out of 21 pairs of forms had statistically significant differences $(p<0.05)$. Specific comparison between any two of seven form formats at each information category level showed that 145 out 210 pairs of forms (69\%) for an information category had statistically significant differences $(\mathrm{p}<0.05)$.

A statistically significant increase in the overall comprehensiveness rate was found in the admission forms in the EHRs compared with paper-based forms ( $40.0 \%$ vs $28.6 \%$, $\mathrm{p}<0.01)$. At the level of information category in a form, significant increases $(\mathrm{p}<0.01)$ in the electronic forms were found in the data categories of 'Admission Details', 'Baseline Health Ranges’, ‘Membership', 'Demographic’, and 'General Contact'. There was a significant decrease with 'Completion of Form' and 'Health History' $(\mathrm{p}<0.01)$. No change was found in the categories of 'Doctor' and 'Legal Contact'. The difference for the category ‘End of Life Wishes’ was not significant. Figure 2 presents the comparison of 
mean comprehensiveness rates between paper-based and electronic admission forms in total and by information categories.

Figure 2. Comparison of mean comprehensiveness rates of admission forms between paper-based records and EHRs in total and by information categories

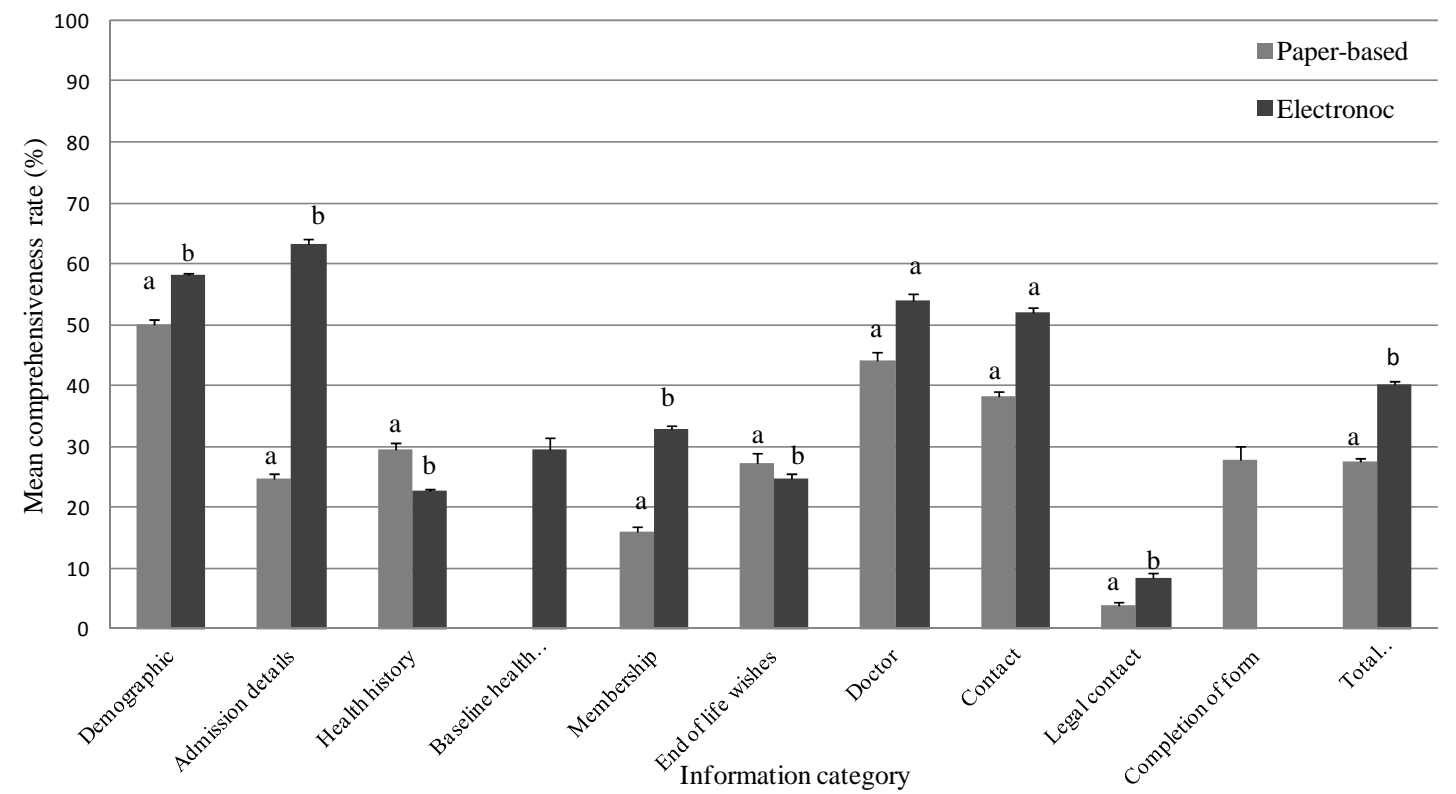

Note: the bar on the top of histogram is standard error

3.4. Frequencies of documented items in admission forms between paper-based records and EHRs

Items of the admission forms were put into seven groups according to their frequency of documentation among the sample forms. Sixteen data elements were frequently recorded (frequency $>70 \%$ ) and 44 were infrequently recorded (frequency $<30 \%$ ) in both documentation systems. Some data elements were frequently recorded in paper-based forms, but were seldom present in EHRs forms, or vice versa. (Table IV.) 
Table III. Distribution of median completeness and comprehensiveness rates (\%), and numbers of items per form among different form formats

\begin{tabular}{|c|c|c|c|c|c|c|c|c|c|}
\hline Information category & Form 1 & Form 2 & Form 3 & Form 4 & Form 5 & e-Form 6 & e-Form 7 & $\begin{array}{c}\text { Total paper- } \\
\text { based }^{2}\end{array}$ & Total EHRs $^{2}$ \\
\hline Sample size & 73 & 18 & 13 & 15 & 28 & 223 & 28 & 147 & 251 \\
\hline $\begin{array}{l}\text { Demographics } \\
\text { Completeness rate (IQR) })^{1} \\
\text { Number of items in the form } \\
\text { Comprehensiveness rate (IQR) }\end{array}$ & $\begin{array}{l}{ }^{\mathrm{a}} 73(9) \\
11 \\
{ }^{\mathrm{a}} 50(6)\end{array}$ & $\begin{array}{l}{ }^{\mathrm{ab}} 81(16) \\
8 \\
{ }^{\mathrm{b}} 44(13)\end{array}$ & $\begin{array}{l}{ }^{\mathrm{a}} 70(35) \\
10 \\
{ }^{\mathrm{bc}} 43(22)\end{array}$ & $\begin{array}{l}{ }^{\mathrm{b}} 89(22) \\
9 \\
{ }^{\mathrm{ace}_{5}} 50(6)\end{array}$ & $\begin{array}{l}{ }_{9}^{c b} 89(22) \\
9 \\
{ }^{b c} 50(13)\end{array}$ & $\begin{array}{l}{ }^{b d} 91(9) \\
11 \\
{ }^{d} 63(6)\end{array}$ & $\begin{array}{l}{ }^{\text {be }} 86(18) \\
11 \\
{ }^{11} 59(13)\end{array}$ & $\begin{array}{l}{ }^{A} 82(16) \\
10 \\
50(13)\end{array}$ & $\begin{array}{l}{ }^{B} 91(9) \\
11 \\
63(6)\end{array}$ \\
\hline $\begin{array}{l}\text { Admission details } \\
\text { Completeness rate (IQR) } \\
\text { Number of items in the form } \\
\text { Comprehensiveness rate (IQR) }\end{array}$ & $\begin{array}{l}{ }^{\mathrm{acd}} 75(0) \\
4 \\
{ }^{\mathrm{a}} 25(0)\end{array}$ & $\begin{array}{l}{ }^{\mathrm{a}} 100(0) \\
3 \\
{ }^{\mathrm{b}} 19(6)\end{array}$ & $\begin{array}{l}{ }^{b} 75(0) \\
12 \\
{ }^{c} 56(6)\end{array}$ & $\begin{array}{l}{ }^{\mathrm{abcd}} 67(0) \\
3 \\
{ }^{\mathrm{bd}} 19(6)\end{array}$ & $\begin{array}{l}{ }^{\mathrm{abd}} 100(0) \\
3 \\
{ }^{\mathrm{be}} 19(5)\end{array}$ & $\begin{array}{l}{ }^{c} 80(0) \\
15 \\
f^{f} 69(6)\end{array}$ & $\begin{array}{l}{ }^{d} 83(0) \\
6 \\
g_{31}(0)\end{array}$ & $\begin{array}{l}{ }^{A} 75(0) \\
4 . \\
{ }^{A} 25(6)\end{array}$ & $\begin{array}{l}{ }^{B} 80(0) \\
14 \\
{ }^{B} 69(6)\end{array}$ \\
\hline $\begin{array}{l}\text { Health history } \\
\text { Completeness rate (IQR) } \\
\text { Number of items in the form } \\
\text { Comprehensiveness rate (IQR) }\end{array}$ & $\begin{array}{l}{ }^{\mathrm{a}} 36(14) \\
14 \\
{ }^{\mathrm{a}} 44(11)\end{array}$ & $\begin{array}{l}{ }^{\mathrm{b}} 50(50) \\
2 \\
{ }^{\mathrm{b}} 17(11)\end{array}$ & $\begin{array}{l}{ }^{c} 100(8) \\
2 \\
{ }^{c d} 22(11)\end{array}$ & $\begin{array}{l}{ }^{d} 33(0) \\
6 \\
{ }^{b c d} 22(11)\end{array}$ & $\begin{array}{l}{ }_{2 \mathrm{ce}} 100(38) \\
2 \\
{ }_{\mathrm{bc}} 22(0)\end{array}$ & $\begin{array}{l}{ }^{f} 67(0) \\
3 \\
d_{22}(0)\end{array}$ & $\begin{array}{l}{ }^{\mathrm{bfg}} 67(0) \\
6 \\
\mathrm{e}_{30}(0)\end{array}$ & $\begin{array}{l}\text { A } 43(33) \\
8 . \\
33(22)\end{array}$ & $\begin{array}{l}{ }^{B} 67(0) \\
3 \\
22(0)\end{array}$ \\
\hline $\begin{array}{l}\text { Baseline health ranges } \\
\text { Completeness rate (IQR) } \\
\text { Number of items in the form } \\
\text { Comprehensiveness rate (IQR) }\end{array}$ & $\begin{array}{l}n / a \\
n / a \\
n / a\end{array}$ & $\begin{array}{l}n / a \\
n / a \\
n / a\end{array}$ & $\begin{array}{l}n / a \\
n / a \\
n / a\end{array}$ & $\begin{array}{l}n / a \\
n / a \\
n / a\end{array}$ & $\begin{array}{l}\mathrm{n} / \mathrm{a} \\
\mathrm{n} / \mathrm{a} \\
\mathrm{n} / \mathrm{a}\end{array}$ & $\begin{array}{l}20(40) \\
5 \\
25(50)\end{array}$ & $\begin{array}{l}\mathrm{n} / \mathrm{a} \\
\mathrm{n} / \mathrm{a} \\
\mathrm{n} / \mathrm{a}\end{array}$ & $\begin{array}{l}n / a \\
n / a \\
n / a\end{array}$ & $\begin{array}{l}20(40) \\
5 \\
25(100)\end{array}$ \\
\hline $\begin{array}{l}\text { Membership } \\
\text { Completeness rate (IQR) } \\
\text { Number of items in the form } \\
\text { Comprehensiveness rate (IQR) }\end{array}$ & $\begin{array}{l}{ }^{\mathrm{a}} 17(0) \\
6 \\
{ }^{\mathrm{a}} 13(0)\end{array}$ & $\begin{array}{l}{ }^{b} 50(33) \\
6 \\
{ }^{b d} 19(13)\end{array}$ & $\begin{array}{l}{ }^{c} 31(12) \\
13 \\
{ }^{c e} 25(16)\end{array}$ & $\begin{array}{l}{ }^{\mathrm{cd}} 33(33) \\
9 \\
\mathrm{bc} 19(19)\end{array}$ & $\begin{array}{l}{ }^{\mathrm{e}} 20(20) \\
10 \\
{ }^{\mathrm{ad}} 13(13)\end{array}$ & $\begin{array}{l}f_{38}(23) \\
13 \\
e 31(19)\end{array}$ & $\begin{array}{l}{ }^{\mathrm{cg}} 29(12) \\
17 \\
\mathrm{e}_{31}(13)\end{array}$ & $\begin{array}{l}\mathrm{A}_{17}(17) \\
8 \\
{ }^{\mathrm{A}} 13(6)\end{array}$ & $\begin{array}{l}{ }^{B} 38(23) \\
13 \\
{ }^{B} 31(19)\end{array}$ \\
\hline $\begin{array}{l}\text { End of life wishes } \\
\text { Completeness rate (IQR) } \\
\text { Number of items in the form } \\
\text { Comprehensiveness rate (IQR) }\end{array}$ & $\begin{array}{l}{ }^{\mathrm{a}} 100(0) \\
2 \\
{ }^{\mathrm{a}} 4(0)\end{array}$ & $\begin{array}{l}{ }^{\mathrm{b}} 40(2) \\
5 \\
{ }^{\mathrm{b}} 40(20)\end{array}$ & $\begin{array}{l}{ }^{b c} 50(0) \\
2 \\
{ }^{c} 20(0)\end{array}$ & $\begin{array}{l}{ }^{\mathrm{bd}} 67(3) \\
3 \\
{ }^{\mathrm{abe}} 40(20)\end{array}$ & $\begin{array}{l}\mathrm{n} / \mathrm{a} \\
\mathrm{n} / \mathrm{a} \\
\mathrm{n} / \mathrm{a}\end{array}$ & $\begin{array}{l}{ }^{d} 50(5) \\
2 \\
{ }^{e} 20(2)\end{array}$ & $\begin{array}{l}\mathrm{n} / \mathrm{a} \\
\mathrm{n} / \mathrm{a} \\
\mathrm{n} / \mathrm{a}\end{array}$ & $\begin{array}{l}{ }^{A} 67(5) \\
2 \\
{ }^{A} 40(40)\end{array}$ & $\begin{array}{l}{ }^{A} 50(5) \\
2 \\
{ }^{A} 20(20)\end{array}$ \\
\hline
\end{tabular}




\begin{tabular}{|c|c|c|c|c|c|c|c|c|c|}
\hline \multicolumn{10}{|l|}{ Doctor } \\
\hline Completeness rate (IQR) & ${ }^{\mathrm{a}} 60(4)$ & ${ }^{b} 13(1)$ & ${ }^{c} 33(2)$ & ${ }^{\mathrm{ad}} 75$ (3) & ${ }^{\mathrm{e}} 0(0)$ & ${ }^{f} 33(0.2)$ & $\mathrm{g}_{1}(0)$ & ${ }^{A} 40(6)$ & ${ }^{A} 50(2)$ \\
\hline $\begin{array}{l}\text { Number of items in the form } \\
\text { Comprehensiveness rate (IQR) }\end{array}$ & 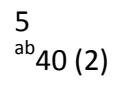 & ${ }^{16} 40(2)$ & $\begin{array}{l}6 \\
{ }^{\mathrm{ac}} 40(3)\end{array}$ & $\begin{array}{l}4 \\
{ }^{\mathrm{b}} 60(4)\end{array}$ & $\begin{array}{l}4 \\
{ }^{c} 40(0)\end{array}$ & $\begin{array}{l}6 \\
{ }^{\mathrm{b}} 40(2)\end{array}$ & $\begin{array}{l}7 \\
d_{1}(0)\end{array}$ & ${ }^{6 .} 40(20)$ & $\begin{array}{l}6 \\
{ }^{B} 40(20)\end{array}$ \\
\hline \multicolumn{10}{|l|}{ General contact } \\
\hline Completeness rate (IQR) & ${ }^{\mathrm{a}} 78(11)$ & ${ }^{b} 28(40)$ & ${ }^{c f} 57(0.21)$ & ${ }^{\text {cdf }} 53$ (29) & ${ }^{\mathrm{ce}} 70(38)$ & $f^{f} 57(24)$ & ${ }^{\mathrm{cfg}} 63(13)$ & ${ }^{A} 71(42)$ & ${ }^{B} 57(23)$ \\
\hline Number of items in the form & 9 & 10 & 21 & & 10 & 21 & 16 & & \\
\hline Comprehensiveness rate (IQR) & ${ }^{\mathrm{a}} 44(6)$ & ${ }^{\mathrm{ac}} 36(24)$ & ${ }^{b} 50$ (19) & ${ }^{\mathrm{bd}} 50(22)$ & ${ }^{c} 22(0)$ & ${ }^{b} 55(22)$ & ${ }^{d} 44(0)$ & ${ }^{A} 39(22)$ & ${ }^{B} 50(22)$ \\
\hline \multicolumn{10}{|l|}{ Legal contact } \\
\hline Completeness rate (IQR) & $\mathrm{n} / \mathrm{a}$ & ${ }^{\mathrm{a}} 0.35(0.20)$ & ${ }^{\mathrm{a}} 0(0)$ & ${ }^{\mathrm{ab}} 0(0.3)$ & ${ }^{b} 0.17(0.3)$ & ${ }^{\mathrm{ab}} 0(1.0)$ & ${ }^{\mathrm{ab}} 0(0.3)$ & ${ }^{A} 0(30)$ & ${ }^{A} 0(100)$ \\
\hline Number of items in the form & $\mathrm{n} / \mathrm{a}$ & 10 & 2 & 4 & 6 & 3 & 4 & 3 & \\
\hline Comprehensiveness rate (IQR) & ${ }^{\mathrm{a}} 0$ & ${ }^{\mathrm{bc}} 0$ (15) & ${ }^{\mathrm{b}} 0(0)$ & ${ }^{c} 8(0.15)$ & ${ }^{c} 8(8)$ & ${ }^{\mathrm{bc}} 0(23)$ & ${ }^{\mathrm{bd}} 0(8)$ & ${ }^{A} 0(0)$ & ${ }^{\mathrm{B}} 0(0)$ \\
\hline \multicolumn{10}{|l|}{ Completion of form } \\
\hline Completeness rate (IQR) & ${ }^{\mathrm{a}} 100(0)$ & ${ }^{\mathrm{ab}} 100(0)$ & $\mathrm{n} / \mathrm{a}$ & $\mathrm{n} / \mathrm{a}$ & ${ }^{c} 50(0)$ & $\mathrm{n} / \mathrm{a}$ & $\mathrm{n} / \mathrm{a}$ & $1(1)$ & $n / a$ \\
\hline Number of items in the form & 1 & 3 & $\mathrm{n} / \mathrm{a}$ & $n / a$ & 2 & $\mathrm{n} / \mathrm{a}$ & $\mathrm{n} / \mathrm{a}$ & 1 & $n / a$ \\
\hline Comprehensiveness rate (IQR) & ${ }^{\mathrm{a}} 33(33)$ & ${ }^{b} 1(42)$ & $\mathrm{n} / \mathrm{a}$ & $n / a$ & ${ }^{c} 33(0)$ & $\mathrm{n} / \mathrm{a}$ & $\mathrm{n} / \mathrm{a}$ & $33(33)$ & $\mathrm{n} / \mathrm{a}$ \\
\hline \multicolumn{10}{|l|}{ Total } \\
\hline Completeness rate (IQR) & ${ }^{a d} 60(10)$ & ${ }^{b} 38(11)$ & ${ }^{c} 56(6)$ & ${ }^{\text {ace }_{51}(22)}$ & ${ }^{c} 52(16)$ & ${ }^{d} 59(11)$ & ${ }^{\mathrm{de}} 60(8)$ & ${ }^{A} 56(14)$ & ${ }^{B} 59(11)$ \\
\hline Number of items in the form & 52 & 63 & 68 & 55 & 46 & 79 & 67 & 54 & 78 \\
\hline Comprehensiveness rate (IQR) & ${ }^{\mathrm{a}} 29(4)$ & ${ }^{\mathrm{a}} 27(9)$ & ${ }^{b} 33(4)$ & ${ }^{\mathrm{a}} 30(7)$ & ${ }^{c} 21(5)$ & ${ }^{d} 41(7)$ & ${ }^{b e} 33$ (4) & ${ }^{A} 28(6)$ & ${ }^{B} 40$ (9) \\
\hline
\end{tabular}

Notes:

1) $\mathrm{IQR}=$ interquartile range

2) Values for number of items in the two Totals columns are the means of values from the seven Form columns

3) Superscripts refer to comparisons of completeness and comprehensiveness rates for different form formats. The same superscript letter for values from different forms indicates that there was no significant difference between them. Different superscript letters for values indicate there was a significant difference in the rates. The same approach has been used in comparison of rates for the total paper based and total EHRs. 
Table IV. Admission form items and groups by level of frequency of documentation ( $n=251$ electronic vs 147 paper-based admission forms)

\begin{tabular}{|c|c|}
\hline Group & items \\
\hline $\begin{array}{l}\text { Items with a high } \\
\text { frequency of } \\
\text { documentation (>70\%) in } \\
\text { both paper-based and } \\
\text { electronic forms }\end{array}$ & $\begin{array}{l}\text { Full name, DOB, gender, religion, marital status, country of birth, aged care facility, } \\
\text { admission date, allergies, medical/surgical diagnosis, Medicare card number, doctor name, } \\
\text { primary contact name, primary contact relationship, primary contact address, primary } \\
\text { contact phone, next of kin name, next of kin relationships, next of kin address, next of kin } \\
\text { phone no. }\end{array}$ \\
\hline $\begin{array}{l}\text { Items with a low } \\
\text { frequency of } \\
\text { documentation }(<30 \%) \text { in } \\
\text { both paper-based and } \\
\text { electronic forms }\end{array}$ & $\begin{array}{l}\text { Resident phone number, secondary language, interpreter needed, working company, other } \\
\text { information, resident UR number, medical record number, external cause of injury and } \\
\text { poisoning, place of occurrence of injury, Flu vaccination, chest x-ray, psychiatric history, } \\
\text { weight, blood sugar level, blood pressure, pension/benefit care number, Australian DVT } \\
\text { card number, hospital insurance, private health insurance provider, private health } \\
\text { insurance/fund number/table, ambulant fund, diabetes association number, election roll, } \\
\text { war service, funeral directive phone number, advanced care directive, summary of wishes, } \\
\text { doctor address, doctor email, primary and secondary contact and next of kin's email and } \\
\text { fax, power of attorney's address and email, guardianship’s name, address, phone and } \\
\text { email, location of will, solicitor's name and phone number, name of nurse completing the } \\
\text { form. }\end{array}$ \\
\hline $\begin{array}{l}\text { Items with a high } \\
\text { frequency of } \\
\text { documentation (>70\%) } \\
\text { only in electronic forms. }\end{array}$ & $\begin{array}{l}\text { Title, preferred name, primary language, Aboriginal or Torres Strait Islander, diet, room, } \\
\text { location, medication trolley, admission status, entry type, resident category, funeral } \\
\text { arrangement, doctor phone, }\end{array}$ \\
\hline $\begin{array}{l}\text { Items with a high } \\
\text { frequency of } \\
\text { documentation (>70\%) } \\
\text { only in the paper-based } \\
\text { forms }\end{array}$ & None \\
\hline $\begin{array}{l}\text { Items with a low } \\
\text { frequency of } \\
\text { documentation }(<30 \%) \\
\text { only in the electronic } \\
\text { forms. }\end{array}$ & $\begin{array}{l}\text { Age, resident usual address, admitted from/source of referral, other health condition } \\
\text { present, drugs on admission, }\end{array}$ \\
\hline $\begin{array}{l}\text { Items with a low } \\
\text { frequency of } \\
\text { documentation }(<30 \%) \\
\text { only in the paper-based } \\
\text { forms }\end{array}$ & $\begin{array}{l}\text { Title, preferred name, diet, room, bed, location, medication trolley, photo taken, admission } \\
\text { status, entry type, resident category, care recipient ID, height, Centrelink number, } \\
\text { Medicare card member number, name as it appears on Medicare card, Medicare card } \\
\text { expiry date, transport access scheme, doctor fax, secondary contact name, secondary } \\
\text { contact relationship, secondary contact address, secondary contact phone number, power } \\
\text { of attorney type, power of attorney name, power of attorney phone number, }\end{array}$ \\
\hline $\begin{array}{l}\text { Items with a frequency } \\
\text { between } 30 \% \text { and } 70 \% \text { in } \\
\text { both paper-based and } \\
\text { electronic forms }\end{array}$ & Pension type, funeral director/undertaker, \\
\hline
\end{tabular}

\title{
3.5. Association between the number of items and the completeness rate and
}

\author{
comprehensiveness rate of admission forms
}

At the level of each information category, the negative association between the completeness rate and the number of items designed in a form was statistically significant 
for paper-based forms (see Table IV, correlation coefficient $-0.26, \mathrm{p}<0.001$ ). This suggests a tendency that increasing the number of items is associated with a decreased completeness rate. No such tendency was identified in electronic admission forms.

The associations between the comprehensiveness rates and the number of items in a form were highly significantly positive at an overall and each information category levels in both paper-based and electronic admission forms (see Table V). This may suggest that increasing the number of items in a form is associated with increased amount of data collected.

Table V. Correlations between the number of items in a form and the completeness and comprehensiveness rates of the form

\begin{tabular}{lllll}
\hline & \multicolumn{2}{l}{$\begin{array}{l}\text { Paper-based } \\
\text { admission forms }\end{array}$} & \multicolumn{2}{l}{$\begin{array}{l}\text { Electronic admission } \\
\text { forms }\end{array}$} \\
\hline \multicolumn{1}{c}{ Correlation variables } & $\begin{array}{l}\text { Correlation } \\
\text { coefficient }\end{array}$ & P value & $\begin{array}{l}\text { Correlation } \\
\text { coefficient }\end{array}$ & $\begin{array}{l}\text { P value } \\
\end{array}$ \\
\hline Total number of items vs overall completeness rate & -0.156 & .06 & -0.024 & .704 \\
\hline Number of items vs completeness rate for each category & -0.260 & $<.001$ & 0.055 & .010 \\
\hline Total number of items vs overall comprehensiveness rate & 0.527 & $<.001$ & 0.451 & $<.001$ \\
\hline Number of items vs comprehensiveness rate for each category & 0.612 & $<.001$ & 0.722 & $<.001$ \\
\hline
\end{tabular}

\section{Discussion}

This study used a qualitative approach to derive a checklist of resident admission data that covers all of the information items in seven admission forms used in nine aged care facilities. The quality of documentation of paper-based and electronic resident admission forms was quantitatively measured and compared to reflect the extent to which resident admission data were recorded. The measurement was undertaken at three levels in each form: overall, by information category and by individual data element. Three measures were used in the study: completeness rate, comprehensiveness rate and the frequency proportion of documented data element. Additionally, the associations between the number of items and their completeness and comprehensiveness rates were identified at 
overall and information category levels for all the forms and between paper-based and electronic systems.

The study identified varying practice among the participating aged care organisations in the documentation of resident background information in the admission forms. In the previous paper-based documentation systems, different formats of admission forms were used across the three aged care organisations. Within each organisation, the format of the admission forms could also be different across the facilities or within each facility.

In Organisation 2, Form 1 was used in Facility E and Form 2 in Facility F, while both these forms were used in Facility C and D. Form 1 was issued under the Nursing Facilities Act 1988 and was used for residents admitted before 2003. Form 2 was designed by the organisation and was introduced later. This reflected a change of the documentation practice in the organisation over time. In Organisation 3, both Facilities $\mathrm{H}$ and I used Form 3, while Facility G used Forms 1, 3 and 4. The reason for this is that Facility G was previously under different management and jointed Organisation 3 in the latter stage. Therefore, different format of forms was found in the facility for the older people who were admitted at different stages. On the other hand, the implementation of the EHR has standardised the format of resident admission forms in Organisations 2 and 3. This should support communication and exchange of information between different organisations and facilities and the use of data for various purposes.

We found that the electronic admission forms had better completeness and comprehensiveness rates than paper-based forms. This evidence was further supported by a comparison of completeness rates between the common items in two pairs of paper- 
based and their electronic derivatives. A higher completeness rate in the electronic forms may suggest that the EHRs more convenient for the nurses to enter data items than using the paper-based record systems. This result is consistent with the previous findings that the use of EHRs was conducive to more complete documentation by health care professionals [12]. An increased comprehensiveness rate in electronic admission forms suggests that more resident admission data were contained in the EHRs. This should facilitate nurses and other care staff in conducting risk assessment and planning more appropriate care to the residents.

Despite the enhanced quality of documentation of resident admission data in the EHRs, the overall completeness and comprehensiveness rates for both paper-based and electronic admission forms were not high. In regard to the completeness rate, only about $56 \%$ of items in the paper-based forms and $60 \%$ of those in the EHRs were recorded. The overall comprehensiveness rate was also low for both paper-based and electronic forms (29\% and 40\% respectively). In the participating RACFs, a resident admission form was usually documented by a registered nurse (RN) or sometimes by an endorsed enrolled nurse (EEN) in the nursing station when the resident was first admitted into the facility. Documentation could also be conducted by a nursing manager in the office. Incomplete documentation can reflect the nurses' poor documentation behavior and implies that the reliability and validity of the information source is compromised [5], indicating a need for improvement.

The quality of nursing documentation is determined by three characteristics: documentation structure and format, documentation process and documentation content [21]. Low completeness and comprehensiveness rates of nursing records identified in this 
study in both the paper-based and electronic forms could be caused by the factors related to the three interrelated characteristics of quality of documentation and need to be effectively addressed by a documentation system. In regard to the structures of the two types of forms that could determine data entry, the paper-based forms provided the opportunity for a nurse to enter several types of data: writing free-text data, selecting answers from several pre-formatted answers with a tick box, or selecting 'yes' or 'no' option to a question. In the electronic medium, a free-text field for a nurse to type in data was available for most items. For some items, a nurse can select answers from a dropdown list or tick box of answers, choose 'yes' or 'no' options by radio buttons.

In terms of documentation process, some nurses' poor typing skill and inability to use the system competently might be the impediment for them to enter data in the computer, with the direct consequence of incomplete documentation. In this situation, providing training to nurses to improve their skills in using electronic systems should be helpful. Increasing nurses' access to the records by placing computers in convenient location in the wards may also facilitate the documentation process.

In relation to the content of documentation, lack of relevance of some data items to a resident's specific situation could be the reason for incomplete documentation. Defining relevant and adequate data items is essential to encourage documentation.

Poor comprehensiveness rate could be caused by the variation in the number and types of data items among different form formats, which had resulted in increased number of data elements in the checklist. Differences in the formats and data items in various admission forms used in different aged care organisations also raise the question of which data items 
are essential for collecting relevant resident data to meet care and management purposes. Unnecessary items in the forms might compromise the privacy of residents and add to nurses' documentation workload, thus being counter-productive through discouraging nursing staff to document.

Resident admission forms contained a wide range of information concepts under 10 categories. It appears that certain items tended to be recorded more often than the others. Frequently collected data items were mainly under the categories of 'demographic', 'general contact' and 'admission details' for both paper-based and electronic forms. Poorly documented data items in both paper-based and electronic forms were mainly under the categories of 'membership' and 'legal contact'. The low completeness could also be caused by the inapplicability of some items to a resident's situation, but the nurses needed to at least document a ' $\mathrm{n} / \mathrm{a}$ ' or 'nil' in the data fields to inform the message receivers that the information items had been reviewed. As many older people in RACFs have poor cognitive capacity [22], incomplete documentation of essential information about them may lead to nurses' lack of comprehensive understanding about the older people's needs and the provision of sub-optimal care to them.

The items under the category of 'baseline health ranges', which were added to one of the EHRs being widely used in seven facilities, were poorly completed. On the other hand, items such as ‘History of Injury’, ‘Flu Vaccination’, ‘Chest X-ray’, ‘Psychiatric Diagnoses' were not formatted in this new EHR. A lack of this information in the current electronic forms may confine the planning of appropriate care to the residents. The solution for this problem may be recording them in other sections of the EHRs such as assessment forms, but this may cause confusion to nurses when retrieving the information 
for immediate use in planning care. Redundancy of documentation could also be a concern if these data were stored in other sections of the systems.

Completeness rate and comprehensiveness rate measured different concepts in this study. Completeness rate can only indicate the extent to which items in a form are documented by a nurse when different formats of forms are compared. A form with a higher completeness rate, but less items may not contain more information than a form with more items, but a lower completeness rate. It could reflect the usefulness of items in a form or the nurses' documentation behavior. On the other hand, a comprehensiveness rate can tell how much information is collected in a form relative to a common checklist and therefore makes different forms with varying number of items comparable.

The results of the correlation analysis described above may indicate that for collecting the same type of information in a paper-based form, increasing the number of items could lead to more data to be captured, though it might cause nurses' reluctance to complete these items, thus resulting in decreased completeness rate of the forms. In contrary, both completeness and comprehensiveness (amount of information) were improved, regardless of the number of items. These relationships between the number of items designed in a form and the completeness and comprehensiveness rates may provide implications for the design of forms.

The study has also identified issues with coding or terminologies in paper-based forms. For example, in Form 1 under the information category of "Health History', several items were designed to capture information about a resident's different diagnoses. The meanings of these items could be overlapped or vague to nurses and this might be the 
reason for the low completeness rate for this information category (36\%). Another example is that items referring to the same concept were given different name in different form formats. For instance, 'Doctor’ was named as ‘Physician’, 'Medical Doctor’, ‘General Practitioner', or 'Medical Officer’ in different forms. Application of standardized terminology would ensure the semantic interoperability of EHRs for communication between systems [23].

There are several limitations to the study. The admission forms were conveniently collected from nine aged care facilities in three organisations. As there was a relatively consistent approach to the documentation in each of aged care organisation, our results are representative of the documentation practice within the participating facilities or organisations. However, the results may not fully reflect the practice of recording resident admission data in other aged care facilities or organisations. Another limitation is that the development of the checklist and the analysis of data did not take into account any mandatory fields of the admission forms. It was assumed that all of the items in a form should be documented, though some items such as ‘Additional Information’ might not be necessary. There are also items such as those about secondary and legal contact and membership details, which might not be applicable for every resident. These items could be considered as not mandatory, thus a distinction between 'not documented' and 'not applicable' could improve the accuracy of this study; however, this information was difficult to retrieve because it was impossible to have a direct contact with the residents and we could not identify a clear guideline for nursing documentation in the participating organisations. This lack of consideration of the difference between mandatory and optional fields may have resulted in a low ranking of quality of documentation for some 
forms. Moreover, the study focused on the occurrence of documentation and did not consider what had been recorded. This could cause bias to the study results if inconsistent or inaccurate information had been recorded.

\section{Conclusion}

Varying documentation practice existed with previous paper-based systems in collecting resident admission information. The implementation of the electronic nursing documentation system standardised various formats of paper-based admission forms across the aged care facilities and organisations. It also contributed to better quality of documentation of resident admission forms, a clear benefit of using EHRs in the aged care facilities. However, the resident admission forms in the EHRs were still incomplete, implying a need for further improvement in documentation practice.

This study analyzed the data coverage of different admission forms and their completeness both in general and in different information categories. The research finding can inform better design of electronic forms.

Further studies are needed on what information is essential to collect from residents on their admission; what factors lead to incomplete documentation in admission forms; what factors cause varying documentation practices and what is the impact of poor documentation on the quality of care and safety of residents.

\section{Acknowledgement}

The study is a part of a broad research project funded by the Australian Research Council and five aged care organisations in Australia. The authors would like to thank the residents and their representatives for giving consent for the research team to collect and 
analyse their records in this study. The authors would also like to acknowledge nurses, nursing managers and management groups of the participant aged care organisations for giving the research team support and access to the aged care facilities to collect research data.

\section{Statement on conflicts of interest}

The authors claim that there is no conflict of interest with conduction of the study.

\section{Summary Table}

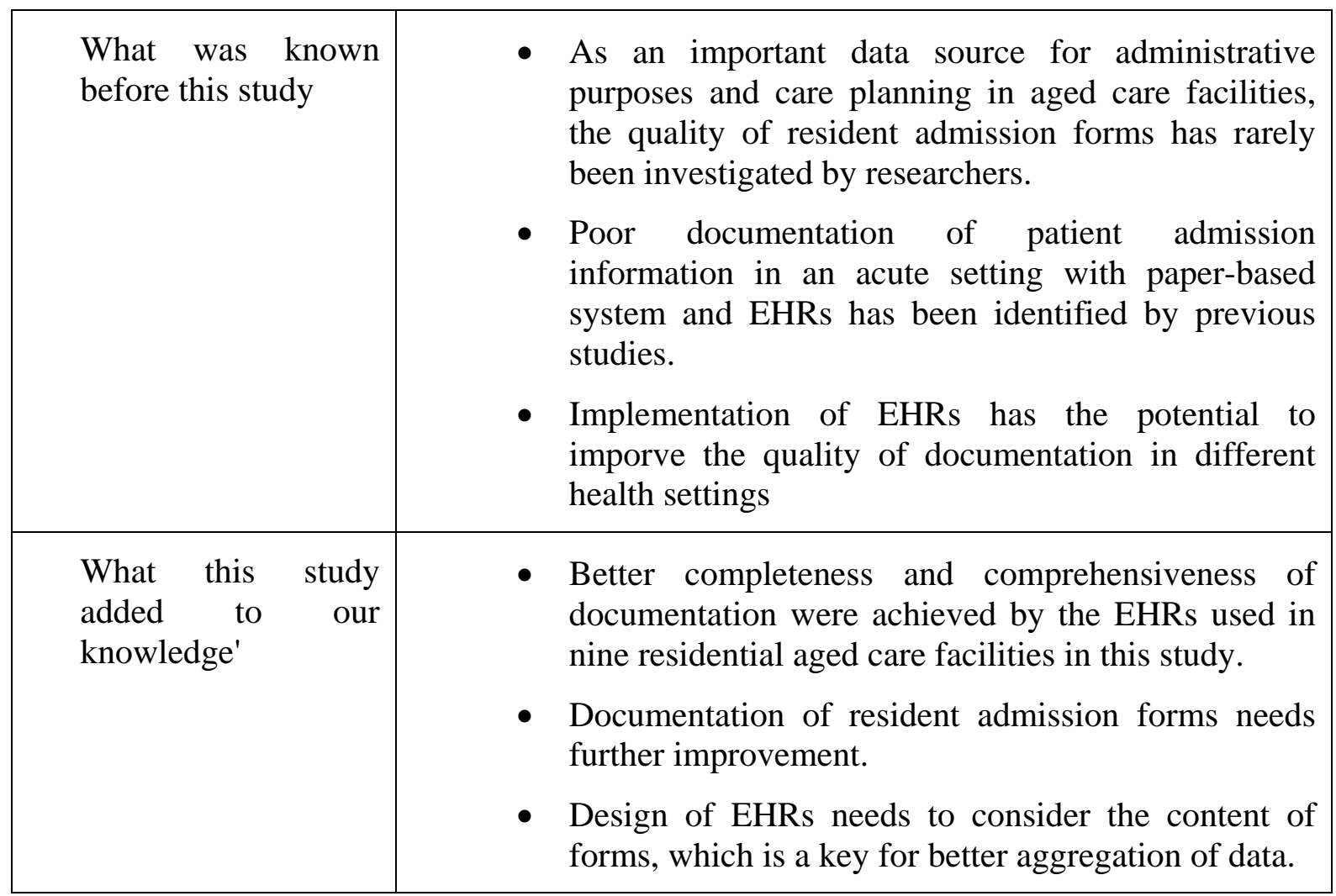




\section{REFERENCES}

[1] C. Oroviogoicoechea, B. Elliott, R.Watson, Evaluating information systems in nursing. Journal of Clinical Nursing 17 (2008) 567-575.

[2] C. Urquhart, R. Currell, M.J. Grant, N.R. Hardiker Nursing record systems: effects on nursing practice and healthcare outcomes. Cochrane Database of Systematic Reviews (Issue1) (2009).

[3] K. Saranto, U.M. Kinnunen, Evaluating nursing documentation - research designs and methods: systematic review. Journal of Advanced Nursing 65(3) (2009) 464476.

[4] H. E. Resnick, B.B. Manard, et al. Use of electronic information systems in nursing facilities: United States. Journal of the American Medical Informatics Association 16(2) (2004) 179.

[5] J. Larrabee, B. Boldreghini, et al. Evaluation of documentation before and after implementation of a nursing information system in an acute care hospital. Computers In Nursing 19(2) (2001) 13.

[6] A. Avidan, C. Weissman, Record completeness and data concordance in an anesthesia information management system using context-sensitive mandatory data-entry fields. International Journal of Medical Informatics 81(3) (2012) 173-181.

[7] E. Ammenwerth, F. Rauchegger, F Ehlerset, al. Effect of a nursing information system on the quality of information processing in nursing: An evaluation study using the HIS-monitor instrument. International Journal of Medical Informatics 80(1) (2011) 2538.

[8] D. Pelleter, C. Duffield, D. Gietzelt et al. The complexities of documenting clinical information in long-term care setting in Australia. Journal of Gerontological Nursing 28(5) (2002) 8-12.

[9] S.Y.S. Jeong, Documentation leads to reform. Geriaction 21(4) (2003), 22-25.

[10] R. Daskein, W. Moyle, D. Creedy Aged-care nurses' knowledge of nursing documentation: an Australian perspective. Journal of Clinical Nursing 18(14) (2009) 2087-2095.

[11] E.N. Munyisia, P. Yu, D. Hailey, The changes in caregivers' perceptions about the quality of information and benefits of nursing documentation associated with the introduction of an electronic documentation system in a nursing home. International Journal of Medical Informatics 80(2) (2011) 116-126. 
[12] K. Hayrinen, K. Sarantoa, P. Nykanen, Definition, structure, content use and impacts of electronic health records: A review of the research literature. International Journal of Medical Informatics 77 (2008) 291-304.

[13] J.L. Callen, M. Alderton, J. McIntosh, Evaluation of electronic discharge summaries: A comparison of documentation in electronic and handwritten discharge summaries. International Journal of Medical Informatics 77(9) (2008) 613-620.

[14] L.S. Chan, N. Schonfeld, How much information is lost during processing? A case study of pediatric emergency department records, Computer and Biomedical Research 26 (6) (1993) 582-591.

[15] K. Yussuff, M. Awotunde, The frequency of drug history documentation in an institutionalized tertiary care setting in Nigeria. Journal of Pharmacy \& Pharmaceutical Sciences. 8(2) (2005) 141-146.

[16] H. Prins, F.H. Kruisinga, H.A. Buller, J.H.M. Zwetsloot-Schonk, Availability and usability of data for medical practice assessment International. Journal for quality in Health Care 14(2) (2002) 127-137.

[17] P. Mbabazi, R. Cassimjee, The quality of nursing documentation in a hospital in Rwanda. Africa Journal of Nursing \& Midwifery 8 (1) (2006) 12.

[18] M. Pringle, P. Ward, C. Chilvers, Assessment of the completeness and accuracy of computer medical records in four practices committed to recording data on computer. The British Journal of General Practice 45 (1995) 537-541.

[19] A. Floor-Schreudering, P.A.G.M. De Smet, H. Buurma, A.C.G. Egberts, M.L. Bouvy Documentation quality in community pharmacy: completeness of electronic patient records after patients' first visits. Annals of Pharmacotherapy 43(11) (2009) 17871794.

[20] T. Schleyer, H. Spallek, P. Hernandez, A qualitative investigation of the content of dental paper-based and computer-based record formats. Journal of the American Medical Informatics Association 14(4) (2007) 515-526.

[21] N. Wang, D. Hailey \& P. Yu Quality of nursing documentation and approaches to its evaluation: a mixed-method systematic review. Journal of Advanced Nursing 67(9) (2011) 1858-1875.

[22] A. Netten, R. Darton, A. Bebbington, J. Forder, P. Brown, K.Mummery, Residential and nursing facility care of elderly people with cognitive impairment: prevalence, mortality and costs. Aging \& Mental Health 5(1) (2001) 14-22. 
[23] L Ahmadian., M. van Engen-Verheul, F. Bakhshi-Raiez, N. Peek, R.Cornet \& N.F. de Keizer, The role of standardized data and terminological systems in computerized clinical decision support systems: Literature review and survey. International Journal of Medical Informatics 80(2) (2010) 81-93. 